\title{
VOCÊ CONHECE SEUS FILHOS? ANÁLISE DE UM DISCURSO DA MÍDIA
}

\author{
DO YOU KNOW YOUR CHILDREN? \\ ANALYSIS OF A MEDIA DISCOURSE
}

Fernando Lefevre ${ }^{1}$

Ana Maria Cavalcanti Simioni ${ }^{2}$

LEFÈVRE. F; SIMIONI, A.M.C. Você Conhece Seus Filhos? Análise de um Discurso da Mídia. Rev. Bras. Cresc. Desenv. Hum., São Paulo, 7 (1), 1997.

\begin{abstract}
Resumo: Buscou-se neste trabalho avaliar um discurso da midia sobre a vida de crianças e adolescentes. Para esta análise foram utilizados, principalmente, os conceitos de idéia central e ancoragem. As seguintes idéias centrais e ancoragens foram encontradas: 1) Idéias centrais: - a vida dupla do jovem; - a naturalização da droga; - o diálogo como ação e como limite para o resgate do jovem. 2) Ancoragens: - o conflito de gerações; - a droga como facilitadora de sociabilidade; - o desenvolvimento da inteligência moral como condição para o resgate da vida social do jovem. Analisou-se também um segmento da reportagem intitulado "O que fazer quando" que revelou um processo de transformação de um discurso de autoridade num discurso autoritário.
\end{abstract}

Palavras-clave: discurso, média, drogas, filhos, adolescentes.

\section{APRESENTAÇÃO}

O presente texto tem como proposta a análise da reportagem "Você conhece seus filhos? Adolescentes revelam o que eles não contam aos próprios pais”, publicada pela revista da Folha de S. Paulo do dia 27 de abril de 1997. Pretendemos aqui mostrar as principais idéias veiculadas e seus desdobramentos.

O texto será dividido em duas partes sendo a primeira constituída pela reportagem em si e a segunda pelo segmento ou sub-matéria que tem por título: "O que fazer quando..."

Para análise da primeira parte do texto foram usados alguns conceitos, que constam em
SIMIONI, et al. 1996, que passa-se a expor a seguir, a fim de que o leitor possa acompanhar o raciocínio desenvolvido.

O primeiro conceito a ser definido é o de “idéia central”. Entende-se por idéia central o conjunto de verdades defendidas pelos autores na elaboração da reportagem. Podem ser uma ou várias idéias (ou verdades).

O segundo conceito é o de "desdobramento”, que se refere ao conjunto de idéias que são oriundas das verdades professadas anteriormente. Assim, como decorrência de uma afirmação ou de uma verdade preferida, surgem idéias que poderíamos denominar desdobramentos ou derivações das idéias principais ou centrais.

1 Prof. Associado do Depto. de Prática de Saúde Pública da Faculdade de Saúde Pública da USP; Coordenador Científico do Centro de Estudos do Crescimento e do Desenvolvimento do Ser Humano - CDH.

End.: Av. Dr. Arnaldo, 715, sala 21, São Paulo - SP - CEP: 01246-904 - Tel/fax: (011) 3061 -3572.

2 Mestre em Saúde Pública pela Faculdade de Saúde Pública da USP; pesquisadora do Centro de Epidemiologia, Pesquisa e Informação da Prefeitura Municipal de São Paulo.

End.: Av. Dr. Arnaldo, 715, $1^{\circ}$ andar, Depto. de Prática, da FSP/USP. São Paulo - SP, CEP 01246-904, Tel: (011) 3066-7743. 
Finalmente, por “ancoragem” denominaremos os fundamentos nos quais se baseia o emissor do discurso; são idéias que funcionam como suportes, que justificam, dão origem ou explicam uma dada afirmação.

\section{DESCRIÇÃO DA REVISTA}

A revista é um encarte da Folha de S. Paulo de Domingo, dia 27/4/97. Tem como matéria principal a reportagem “Que juventude é esta?”, concebida por seis autores. Esta matéria central é entremeada por outros artigos menores, "Cada família uma medida”, "Psiquiatra de Harvard alerta para a inteligência moral”, "Uso moderado de drogas nem sempre é problema”, que funcionam como exemplos ou como apoios teóricos às teses (aqui por nos definidas como idéias centrais) que os autores pretendem defender. Paralelamente a estes artigos encontramos uma submatéria assinada por uma psicóloga sob o título "O que fazer quando ...” estruturada sob a forma de perguntas e respostas.

Quanto à forma, algo que nos parece importante observar é que o texto apresenta uma disposição que induz o leitor ao desenvolvimento de um raciocínio que o leva à idéia ou verdade que os autores professam. Com efeito, à medida que uma determinada idéia é professada, ela é precedida ou sucedida por um depoimento, de forma a mostrar ao leitor que a tese do autor é comprovável na realidade cotidiana do jovem, e por analogia, do “seu”jovem, isto é, do eventual filho(a) do leitor(a). Ao mesmo tempo são colhidos depoimentos concedidos por autoridades técnicas (professores e técnicos de prestígio) que "garantem" ao leitor a veracidade das teses apresentadas pelos autores da reportagem.

Como não é objeto deste estudo a analise de imagens (que passam deste a sugestã da marginalidade até a da família tradicional incluíndo "carimbo" de Harvard com a figura do tradicional psiquiatra), passaremos à análise de conteúdo de discurso.

\section{ANALISE DO DISCURSO}

A análise da primeira parte do trabalho será feita segundo o referencial conceitual apresentado no começo do trabalho. Para o desenvolvimento do mesmo seguiremos o seguinte esquema:

- inicialmente serão apresentadas as idéias centrais do texto;

- a seguir demonstraremos em quais pressupostos as idéias centrais estão apoiadas;
- para finalizar será feita a análise dc desdobramentos, isto é, quais são as idéias d rivadas das idéias centrais.

Na segunda parte do discurso serão examinadas algumas características internas do discurso e o papel da autoridade científica no interrior do discurso midiático.

\section{PRIMEIRA PARTE: ANÁLISE DO CORPO DA REPORTAGEM}

\subsection{Idéias Centrais} centrais:

O artigo contém basicamente três idéias

- A “vida dupla” do jovem;

- A naturalização da droga;

- O diálogo como ação e como limite para o resgate dojovem.

\subsubsection{Primeira idéia central: a "vida dupla" do jovem}

A primeira afirmação que aparece no texto: “Você conhece seus filhos?” e que serve de título à reportagem já explicita a idéia de vida dupla do jovem. Esta afirmação é reforçada na chamada menor" Adolescentes revelam o que eles não contam aos seus próprios pais” Implicitamente estes textos remetem o leitor à seguinte mensagem: "você agora vai saber aquilo que o seu filho não te conta”. Para reforçar esta mensagem, a chamada menor, que completa a pergunta incial liga-se diretamente à mensagem da página posterior: "Nos finais de semana Beto vira outra pessoa”.

O texto vai ligando uma mensagem a outra de forma a mostrar ao leitor (aos pais) que eles não conhecem inteiramente seus filhos e que há sempre um outro (filho) desconhecido, ao qual os pais não tem acesso. "Às 6h de Domingo ele volta para casa, enquanto os pais estão dormindo. Beto diz que eles nem imaginarn como o filho se diverte". Esta idéia é descrita na pág. 10 com clareza: “cerca de á45 depoimentos reunidos pela Revista da Folha mostram que mesmo quando não esbarram na criminalidade os adolescentes escondem uma vida dupla ou evitam contar aos pais muitas das experiências pelas quais estão passando”.

Poderíamos continuar apresentando os inúmeros exemplos que o texto retrata de depoimentos onde os jovens deixam claro que levarn uma outra vida que não é acessível aos pais. Vamos à guisa de concluir este tópico citar o depoimento da pág. 13: "É ruim não poder revelar em casa quem eu realmente sou” ou o depoimento inicial da pág. 8 "de segunda a sexta, trabalha, estuda e volta sossegado para casa... sábado à tarde, sai de 
casa para encontrar os amigos, dar um rolê e zoar. Nessas voltas usa droga... bebe e dança muito...”.

4.1.1.1. ancoragem: o conflito degerações, isto é, os pais enquanto autoridades questionáveis

A ancoragem, como já foi dito anteriormente, diz respeito às idéias que dão suporte às verdades explicitadas pelo emissor do discurso. Poderíamos imaginar que todo discurso é sempre ancorado, pois todo sujeito ao emitir uma afirmação o faz baseado em algum juízo de valor, conceito ou pré-conceito que possua a respeito das coisas.

Aqui só apresentaremos ancoragens onde o emissor do discurso as explicitou com clareza. Não será objeto desta análise suposições de prováveis ancoragens. Portanto só consideraremos as ancoragens nas quais os autores expressaram um discurso observável.

Segundo os autores do texto, a necessidade que tem os jovens de viver uma vida dupla poderia ser explicada como um conflito de gerações, onde o mundo (aqui entendido como conjunto de valores adotados pelo indivíduo) dos pais seria diferente do vivido pelo jovem do mundo de hoje. Alguns depoimentos extraídos do texto servem como exemplo:

"Minha visão sobre drogas é totalmente diferente da deles. (os pais). Eles não encarariam numa boa. Minha mãe usa termos como maconheiro e acha que a droga destrói a vida “.

Em outro ponto do artigo podemos extrair outro depoimento que nos leva a esta conclusão: "um dia, minha mãe achou um saquinho de erva nas minhas coisas, mas eu disse que era chá, e ela acreditou”.

A mesma afirmação usada à respeito da droga também serve para explicar o distanciamento das gerações em relação ao sexo. Podemos verificar isto no depoimento transcrito a seguir:

"O que custa a entrar na cabeça deles é essa história de a gente estar namorando numa semana não estar na outra e, na próxima, estar transundo com uma pessoa diferente. Afinal eles (os pais) não são da geração da camisinha...”

Em outro trecho do discurso da mesma depoente. a ancoragem é bem claramente definida... "é ruim não poder revelar em casa quem eu sou, mas prefiro manter a minha individualidade, mentindo... só falo o que sei que eles vão aprovar. Meu pai tem 60 anos, não posso abusar do coração dele."

Os autores ancoram a necessidade de vida dupla, na tese do conflito de gerações pois uma vez que os pais possuem um outro conjunto de valores de vida isto explicaria a necessidade do jovem em não mostrar a eles quem realmente é.
Para o jovem o conflito é apresentado com a seguinte pergunta: Como escapar do curso natural de uma dada geração, em um dado tempo, descompassado do tempo da geração dos pais?

\subsubsection{Segunda itleia central: a naturalização da droga}

A segunda idéia central apresentada pelos autores, é que para esta geração a droga é natural, isto é, faz parte do cotidiano da vida de qualquer jovem. Podemos verificar esta afirmação nos discursos abaixo;

“...aconteceu ao mesmo tempo com todo mundo. A coisa pegou; agora é filmar e beber direto até às 5 h."

“...Droga é o que não fàlta na noite. Sexo rola, mas não rola direto.”

“... Se rolar briga, é briga, se rolar sexo é sexo, se for droga é droga..."

“... hoje é uma coisa comum. E difi cil um aelolescente que nunca tenha experimentado... “

“... eles (os pais) São de uma geração em que maconha era coisa de marginal. Hoje todo mundo fuma e cheira..."

Verificamos pela "naturalidade” que os discursos acima são apresentados ao leitor, que os autores defendem a idéia de que a droga existe hoje naturalmente na vida de todos os jovens, assim como o sexo ou as brigas.

\subsubsection{1. ancoragens}

A idéia de naturalização da droga segundo os autores, está ancorada em duas teses:

a) a droga como facilitadora da sociabilidade do jovem; limites.

b) a droga como sinal de ultrapassagem de

\section{a) A droga como facilitadora da sociabilidade do jovem}

A primeira ancoragem que encontramos está ligada ao fato do adolescente usar a droga hoje como fazendo parte, de modo natural, do seu mundo cotidiano já que diz respeito a ela ser "gasolina” ou combustivel necessário para gerar desinibição, condição por sua vez necessária para o bom desempenho nas suas atividades de lazer e sociabilidade. Os discursos abaixo explicitam esta idéia adotada pelos autores da reportagem, apoiados na fala de uma autoridade "científica":

"... se o adolescente tem uma viela social normal e vai bem no colégio não sei porque se preocupar com o que é denominado uso recreativo de drogas..."

“...diz que o consumo moderado de drogas por adolescentes com uma vida saudável nem sempre é um problema..." 
Na matéria em que temos os depoimentos dos jovens podemos analisar o seguinte discurso: "... ele define a roleta russa de aventuras do sábado a noite com a eloqüencia juvenil: a gente vem pura zoar... no elomingo, ele volta para casa...”

\section{b) A droga como ultrapassagem de limites}

O texto também coloca outra ancoragem para o uso da droga: é quando ela assume para o adolescente o caráter de transgressão, de vício, levando-o muitas vezes à prisão. Sob este ponto de vista ela teria uma utilização muito diferente do uso que faz Q jovem que simplesmente a vê como um combustível para o lazer, para a diversão. Esta idéia é claramente explicitada neste depoimento transcrito a seguir:

“... a cocaína veio depois. Cheirava um grama a cada hora. Enquanto havia dinheiro para comprar eu não parava... o que caia na minha mão eu cheirava..."

“... só há problema quando o uso é abusivo. Se o adolescente apresentar uma socialização complicada - poucos amigos ou namorados e estiver indo mal no colégio, deve-se procurar um analista para que ele faça uma avaliação...”

Neste comentário também notamos a necessidade dos autores reforçarem a sua tese com o apoio do depoimento de um especialista. Este deixa claro no seu discurso a teoria do uso da droga, não só como lazer mas ligada a comportamentos desviantes os quais requerem o auxilio de um terapeuta.

\subsubsection{2. desdobramentos: a turma como protetora e como incentivadora da violência e da droga}

O uso da droga concebido como natural para o jovem do mundo moderno está apoiado na necessidade de ser aceito pela "turma". A reportagem desdobra a idéia de naturalização em outra que é imprescindível à necessidade de amparo e apoio que tem o jovem. Quem desempenha este papel é, segundo os autores, "a tunna".

O texto traz, portanto, como desdobramento a importância da "turma" como elemento protetor mas ao mesmo tempo incentivador do uso da droga e da violência:

“... algumas vezes, envolve-se em brigas, mas conta com a turma para não terminar no maior preju."

"... somos da mesma turma da rua. Éramos caretas... há dois anos o pessoal começou a pegar o carro dos pais e comprar lança-perfume. Aconteceu ao mesmo tempo, com todo mundo. A coisa pegou, agora é fumar e beber direto..."

\author{
"... Alexandre conta que começou afumar \\ com os amigos.”
}

4.1.3. Terceira idéia central: o diálogo, como ação e como limite para o resgate do jovem

A terceira idéia veiculada na reportagem encerra a solução aos problemas levantados pela primeira e segunda idéias centrais. Enfim o texto aponta para a chave de como vencer a distância entre o universo cultural de pais e filhos, distanciados não só pela idade mas pela diversidade. A fórmula apresentada é a do diálogo, mas um diálogo diferente, baseado muito mais na conduta e na ação do que na palavra. O exemplo aparece como mais potente do que o discurso.

“.. em linhas gerais, reafirmam a velha tese de que não adianta nada o faça o que eu digo, mas não faça o que eu faço..."

“... qualquer lição dada abstratamente a uma criança não adianta muito... meu filho não disse nada, mas eu senti que ele estava me observando..."

O diálogo estabelecido através da ação também contém a idéia de estabelecimento de limites, segundo os autores:

“... é preciso ter clareza do seu papel de adulto. O adolescente, quando procura o pai ou o professor, não quer um coleguinha porque já tem vários... ele quer alguém que exponha os limites comclareza..."

"... os especialistas recomendam... compreensão e supervisão...”

E importante notar que o texto usa o termo “exponha” e não "imponha” em relação aos limites, deixando claro quanto a necessidade do jovem apreender porque são estabelecidos limites.

\subsubsection{1. ancoragem: o desenvolvimento da in- teligência moral como condição para o resgate da vida social do jovem}

Interessante também notar que para o resgate do diálogo com o jovem, o texto faz referência aos especialistas, como recomendadores. Para continuarmos esta análise passemos à ancoragem que está ligada a esta idéia central.

Segundo o texto, ancorando a idéia do “diálogo" como forma de resgate do jovem, está a tese que defende a necessidade do desenvolvimento da inteligência moral, como norteadora da conduta da criança e do jovem.

“... os educadores... esquecem por completo da esfera moral, com resultados como os incidentes da semana passada no Brasil..."

“... mesmo antes de um menino ou menina nascer, seus pais já estão dando expressão a seus valores de uma forma que vai ser importante a seu filho ou filha..." 
“... em seu livro Coles afirma que o exemplo dos adultos em casa, na escola e na comunidade é essencialpara estimular a fnteligência moral, que a criança começa a desenvolver mesmo antes de ter aprendido a se comunicar com palavra..."

\subsection{Conclusão}

A fim de que possamos visualizar com clareza a "desconstrução" proposta neste estudo, será apresentado um quadro que possibilita ao leitor refazer o trajeto percorrido no decorrer da análise.

O quadro abaixo nos mostra as teses defendidas pelos autores, isto é, as idéias centrais.

\begin{tabular}{|l|l|l|}
\hline \multicolumn{1}{|c|}{ Idéia Central } & \multicolumn{1}{|c|}{ Ancoragem } & Desdobramento \\
\hline $\begin{array}{l}\text { 1. A vida } \\
\text { dupla do jovem }\end{array}$ & $\begin{array}{l}\text { O confltio de gerações, } \\
\text { isto é: os pais enquanto } \\
\text { autoridades } \\
\text { questionáveis }\end{array}$ & $\begin{array}{l}\text { Sem } \\
\text { desdobramentos }\end{array}$ \\
\hline $\begin{array}{l}\text { 2. A naturalizacao } \\
\text { da droga }\end{array}$ & $\begin{array}{l}\text { A droga como facilitadora } \\
\text { da sociabilidade do jovem } \\
\text { A droga como } \\
\text { ultrapassagem de lirnites }\end{array}$ & $\begin{array}{l}\text { A turma como } \\
\text { protetora e incen- } \\
\text { tivadora da vio- } \\
\text { lência e da droga }\end{array}$ \\
\hline $\begin{array}{l}\text { 3. 0 diabgo como } \\
\text { açao e como limite } \\
\text { para o resgate do } \\
\text { jovem }\end{array}$ & $\begin{array}{l}\text { O desenvolvimento da } \\
\text { inteligência moral como } \\
\text { resgate da vida social para } \\
\text { o jovem }\end{array}$ & $\begin{array}{l}\text { Sem } \\
\text { desdobramentos }\end{array}$ \\
\hline
\end{tabular}

O texto utiliza o depoimento como forma de produzir um efeito de verossimilhança, isto é, levar o leitor a ter a sensação de que aquilo que se afirma é verdade. Resta-nos a pergunta: É mesmo verdade?

Nesse sentido, fica aqui o seguinte questionarnento: em princípio, os sujeitos entrevistados poderiam ser considerados sujeitos sociais e como tal seu discurso poderia ser atribuído a um determinado grupo. Porém, a reportagem não oferece dados que ao menos sugiram que os entrevistados tenham recomposto o universo dos adolescentes, de modo que este discurso com suas idéias, desdobramentos e ancoragens pudesse ser atribuído à maioria dos adolescentes, incluindo aí, como promete a reportagem, o filho do leitor...

Não há dúvida que existem adolescentes que levam uma vida dupla: a reportagem apresenta depoimentos que indicam claramente isso. Porém, para quantos isso é verdade? A reportagem parece estar muito mais interessada em apresentar do que em comprovar "sua" verdade.

\section{SEGUNDA PARTE: ANÁLISE DO SEGMENTO: “O QUE FAZER QUANDO...” (segundo a psicóloga Rosely Sayão)}

O segmento em questão é parte da reportagem geral que se está analisando, ocupando uma faixa equivalente a um terço das págs. 10 e 11 (a reportagem desdobra-se da pág. 8 à 16).

Diferentemente do corpo da reportagem (preto em fundo branco), o texto apresenta-se em negrito contra fundo azul. O título: - "O que fazer quando...” aparece destacadarnente em letras brancas contra fundo vermelho e cada um dos problemas/soluções, começando por pontos de suspensão, "encadeia" nos pontos de suspensão do título genérico.

São oito problemas que a reportagem ou a própria psicóloga elegeu como merecedores de respostas em termos de conselhos especializados já que se uma psicóloga esta enunciando "o que fazer quando...” é porque os pais "leigos" não estão, cspontaneamente, sabendo direito o que fazer quando ...

Vamos apresentar inicialmente um quadro geral e em seguida uma análise detalhada de cada um destes pares: problema / solução.

\subsection{Quadro Síntese da Matéria (Pág. seguinte)}

\subsection{O Que Fazer Quando...}

\subsection{1. “... Você notou maconha na gaveta de seu filho?”}

Antes de analisar a resposta convém mencionar que a pergunta tem como pressuposto que você, pai ou mãe, andou, de uma forma ou de outra, espionando a gaveta de seu filho. Com efeito, se você "achou” algo na gaveta é porque "procurou”. Pergunta-se: É lícito os pais espionarem as gavetas dos filhos? Implicitamente a psicóloga está concordando.

Resposta da psicóloga: “Tem de falar com ele. Afinal, a casa é dos pais. Imponha limites. Cada pai faz de um jeito. uns conversam, outros mandam para o psicólogo, outros brigam, se cles esperam. Mas é preciso se manifestar para não perder a autoridade. O faz-de -conta-que-não-vi, para o adolescente, significa descaso ou aprovação".

É preciso e mesmo obrigatório falar com ele sobre a maconha encontrada porque a casa é dos pais? O que quer dizer isto? Que portar maconha em casa é um problema porque a casa não é do filho?

Qualquer coisa, o desespero, a briga, o mandar para o psicólogo é válido, melhor que a inação por que esta significa, sempre, o não exer- 


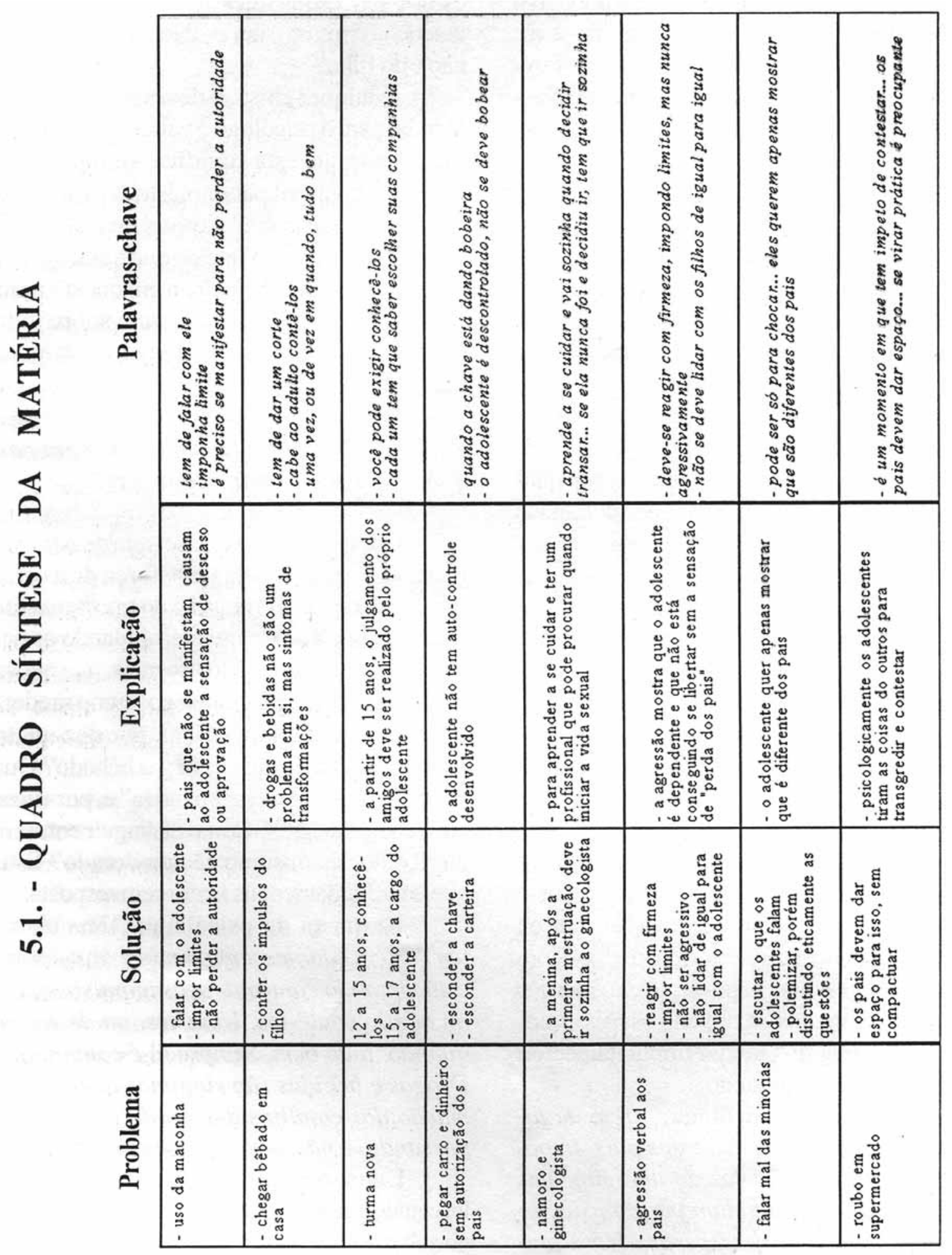


cício do papel paterno, isto é, a hipocrisia do "fingir que não viu”. O problema não parece ser a maconha mas o fato de que a sua existência na gaveta do filho coloca em questão a autoridade dos pais sobre a casa e sobre todos os subordinados que nela habitam.

\subsection{2. “... Seu fillho chega bêbado em casa quatro fins-de-semana seguidos?”}

Compreende-se que se trata de uma pergunta que contém nela uma força de expressão. Mas com tal formulação do tipo "quantitativo" não se está, certamente, ajudando os pais da maioria dos filhos adolescentes, que bebem moderadamente, a distinguir consumo moderado de não moderado. Afinal, por que quatro fins de semana? O que é chegar bêbado? Qual a diferença entre "chegar bêbado" e, por exempio, "chegar alegre”? Como distinguir consumo moderado de consumo não moderado? Estas questões fundamentais ficam sem resposta.

Resposta da psicóloga: “Tem de dar um corte. O adolescente ainda é alguém que está tentando controlar seus impulsos. Cabe ao adulto contê-los. Uma vez, ou de vez em quando, tudo bem. Sempre já é complicado. Drogas e bebidas são sintomas de transformação dos conflitos que o adolescente está passando, e não um problema em si."

É de se observar a rigidez de papéis: adolescente "ainda não-ser”, que apenas "se comporta” x adulto "ser”, que age racionalmente.

Drogas são sempre sintomas de transformação dos conflitos adolescentes? O que quer dizer' transfonmaçao de conflitos”? Consumo de drogas pelo adolescente não poderia ser, por exemplo, sintomas de reação deste adolescente a conflitos que se passam com seus pais?

\subsection{3. “... Seu filho está com uma turma nova, gente que você não conhece?”}

Resposta dó psicóloga: "Na primeira fase da adolescência, que vai dos 12 aos 15 anos, você pode exigir conhecê-los, pois precisa ter cuidado. Na segunda fase, dos t5 aos 17 anos, não. Os pais têm de ir sempre conversando. É um erro julgar os amigos dos filhos. Cada um tem de saber escolher suas companhias".

Dos 12 aos 15 anos você precisa ter cuidado com seus filhos dos 15 aos 17, não.

É, sempre, um erro julgar os amigos dos filhos ou apenas dos filhos de 15 a 17 anos?

5.2.4. “... O filho pega o carro escondido e começa a sumir dinheiroro da carteira”.

Resposta da psicóloga: “Ele só pega o carro quando a chave está dando bobeira. É a mes- ma coisa que os pais que reclamam que está sumindo dinheiro da carteira. O adolescente é descontrolado, não se deve facilitar."

O adolescente pegar o carro escondido e/ ou roubar dinheiro da carteira dos pais, comportamentos notoriamente delinqüentes, fazem parte de um de seus atributos normais, isto é, do descontrole! Aqui - onde seria de se esperar - não aparece a necessidade dos pais conversarem com o adolescente: basta não deixar a chave do carro ou a carteira "dando bobeira”.

\subsection{5. “... A sua filha começou a namorar. Devo levá-la ao ginecologista?”}

Resposta da psicóloga: "O ideal é que, quando a menina menstrua, ela já vá ao ginecologista. Assim, aprende a se cuidar e vai sozinha quando decidir transar. Não é bom que a mãe se antecipe, até porque pode ser que ela começe a namorar e não transe logo de cara. Mas, se ela nunca foi e decidiu ir, tem que ir sozinha."

Quando a menina menstrua deve-se levála ao ginecologista; assim ela aprende a se cuidar e vai sozinha quando decidir transar. Trata-se de um encadeamento totalmente arbitrário de idéias porque a menina que menstrua precisa ir ao ginecologista para supostamente aprender a se cuidar? Quem garante que, após ir pela primeira vez ao ginecologista, necessariamente, quando decidir transar, ela irá, sozinha ou aeompanhada, ao ginecologista?

Por que, quando ela decidiu transar, não pode ir acompanhada da mãe ao ginecologista?

Na suposição de que o segmento: Mas, se ela nunca foi e decidiu ir, tem que ir sozinha, a despeito da impropriedade lógica deste "nunca foi e decidiu ir”, signifique algo, qual a relação existente entre "decidir ir" ao ginecologista e "ter que ir sozinha”? Se a menina decidiu ir ao ginecologista por que não pode pedir à mãe que vá junto?

\subsection{6. “... Os filhos começam a agredir} verbalmente os pais..."

Resposta da psicóloga: “Mostra que o adolescente ainda está dependendo dos pais, não está conseguindo se libertar. Deve-se reagir com firmeza, impondo limites, mas nunca agressivamente - não se deve lidar com os filhos de igual para igual. Não é fácil para o adolescente "perder " os pais, então ele se torna agressivo.”

Mais uma vez um tipo de resposta estereotipada: deixando de lado o fato de que "agressão verbal aos pais" pode representar coisas bastante distintas, dependendo inclusive daquilo que os pais considerarem como limite onde começa e acaba o comportamento verbal agressivo, um suposto comportamento verbal do adolescente em rela- 
ção a seus pais pode, por exemplo, ser motivado por um ambiente agressivo em casa; por um temperamento agressivo de um dos pais; por um temperamento próprio do adolescente, etc.

\subsection{7. “... Seus filhos começam a falar mal de negros pobres ou homossexuais.” \\ Resposta da psicóloga: "Os pais têm que} escutar o que os filhos estão dizendo. Muitas vezes eles querem apenas mostrar que são diferentes dos pais. E preciso polemizar, mas não ir pelo lado. "Como você meu filho, pode pensar assim? “... Pode ser só para chocar. Mas os pais têm sempre de estar discutindo no dia-a-dia essas questões éticas.”

Mais uma vez não é apresentado mesmo um esboço de justificativa para "o que fazer e o que não lazer' '. Por que é vetada, por exemplo, a indignação moral dos pais diante de atos de racismo e preconceito?

\subsection{8. “... Seu filho começa a roubar coisas do supermercardo?”}

Resposta da psicóloga: "Pelo lado psicológico. o adolescente tem de tirar coisas dos outros. É um momento em que tem o ímpeto de contestar, transgredir Os pais devem dar espaço para isso, não $\wedge \mathrm{S}$ não compactuar. Se isso virar uma prática, é preocupante.”

O que é e como dar espaço para a transgressão mas não compactuar com ela?

\subsection{Conclusão}

Em conclusão pode-se observar que uma série de escolhas encadeadas condicionando-se mutuamente levam quase que necessariamente à produção de tal discurso autoritário.

Por uma deturpação de sua missão, a média muitas vezes acaba não produzindo conhecimento mas noticia (como se estas duas missões não pudessem ser conciliadas...), isto é, fatos midiáticos, como, no caso, o que poderíamos denominar de "o lado oculto (dos pais) do bom adolescente”.

Neste contexto de fatos midiáticos ganha sentido uma submatéria como: "o que fazer quando...” do tipo "jogo rápido” de perguntas e respostas - bastante típico da média comum às oito situações/soluçõcs que se considera típica da adolescência. E nesse sentido podemos enunciá- lo como consistindo no processo de transformação ou fissão do discurso de autoridade num discurso autoritário? com a presença atestada no discurso das seguintes marcas de autoridade/ autoritarismo:

- os pais não sabem o que fazer e a autoridade sabe e diz, pontificando;

- os discursos são reiteradamente enunciados na forma imperativa;

- há, em geral. apenas uiva coisa a ser feita

- há, em geral uma causa básica para o comportamento adolescentc;

- todos os adolescentes são basicamente iguais;

- as alirinativas (conselhos) são apenas enunciadas, sem justificativas maiores;

- os papéis do adolescente c dos pais são estereotipados e cristalizados: os adolescentes são "o problema" (se drogam, roubam, etc.) e os pais “a solução” (contêm os transbordamentos, cortam a droga, etc.).

Podemos então colocar que a análise desta submatéria revela a presença de um certo tipo de discurso autocentraclo ou referido (FAUSTO NETO, 1996) onde o que importa, acima de qualquer coisa, acima do conhecimento, da verdade, do bom sensos é a noticia, a reportagem "bombástica”, contando a mídia para isso com a cooptação da autoridade científica (no caso uma psicóloga) que fornece respaldo eientífico à apologia da notícia.

Com isso não estamos dizendo, de modo algum, que toda a mídia se comporta assim, nem muito menos que a "apologia do fato" seja uma caractcrística inerente do discurso midiático.

Ao contrário, cremos firmcmente que se os fatos são (e devem continuar sendo) a matéria prima da midia, ela pode trabalhá-los sem que necessite sempre hipertrofiá-los ou buscar justificálos com um mero apelo formal à autoridade científica. A mídia pode, perfeitamente, trabalhar os fatos e notícias com vistas a que possam "sair para fora” do factualismo empirista e inconseqüente, gerando-sc conhecimento (sobre a adolescência, por exempio) a partir destes fatos e notícias.

É que é na linha da cooperação, e não da troca mútua de favores, que a mídia e a ciência devem trabalhar, buscando-se conciliar notícia e conhecimento em benefício do dcsenvolvimento do gênero humano. 


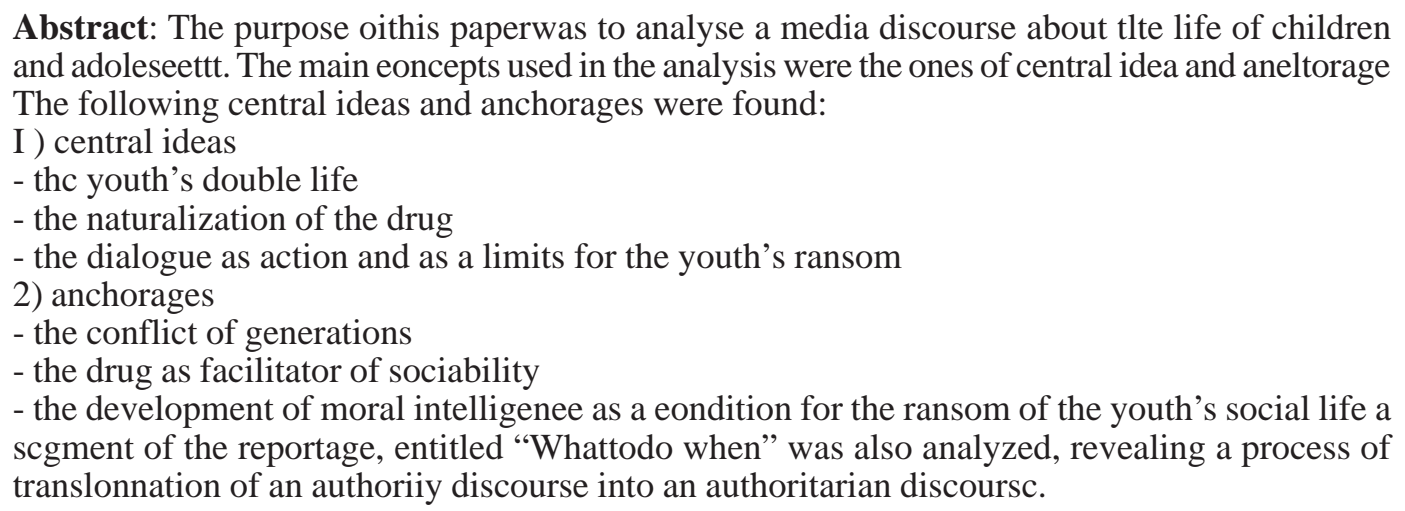

Key-words: media, discourse, drugs, childrem adolescents.

\section{REFERÊNCIAS BIBLIOGRÁFICAS}

FAUSTO NETO, A. O Impeachment da televisão. Como se cassa um Presidente. Rio de Janeiro, Diadorin Editora. 1995.

SIMIONI, A. M. C; LEFÈVRE, F; BICUDO FEREIRA, I. M. T. Metodologia qualitativa nas pesquisas em saúde coletiva: considera- ções teóticas e instrumentais. São Paulo, Faculdade de Saúde Pública da USP/Departamento de Prática de Saúde Pública. Série Monográfica N², 1996. 97

Recebido em 05/06/97

Aprovado em 15/08/97 